\title{
Denitrogenation (or Oxyfuel Concepts)
}

\author{
M. Anheden ${ }^{1}$, Jinying Yan ${ }^{1}$ and G. De Smedt ${ }^{2}$ \\ 1 Vattenfall Utveckling AB, SE-162 87 Stockholm - Sweden \\ 2 Air Liquide R\&D, Centre de recherche Claude-Delorme, 1, chemin de la Porte des Loges en Josas, 78354 Jouy-en-Josas Cedex - France \\ e-mail: marie.anheden@vattenfall.com - jinying.yan@vattenfall.com - guillaume.de-smedt@airliquide.com
}

Résumé - Capture par oxy-combustion - La capture par oxy-combustion consiste à séparer l'oxygène de l'azote avant la combustion. On obtient ainsi un $\mathrm{CO}_{2}$ concentré, facile à séparer en fin de combustion. Cette technologie a été utilisée dans l'industrie du verre, mais nécessite des développements importants pour une application à grande échelle à la génération d'énergie, en particulier au niveau de l'unité de séparation de l'air : des technologies de séparation par membranes, d'adsorption de l'oxygène à haute température et de distillation cryogénique sont à développer.

\begin{abstract}
Denitrogenation (or Oxyfuel Concepts) - Denitrogenation or oxyfuel combustion is based on separation of oxygen from nitrogen before combustion. The $\mathrm{CO}_{2}$ obtained is concentrated and easy to isolate after combustion. Oxyfuel combustion has been used in different industrial applications, although technological challenges have to be met for large scale power generation. An important area of improvement of this concept is to be found in the air separation unit, with the help of new technologies like membrane separation technologies, high temperature oxygen adsorption technologies, and improved cryogenic distillation.
\end{abstract}




\section{BASIC PROCESS AND ENERGY CONVERSION DESCRIPTION}

Oxyfuel combustion has been used for several years in glass furnaces to improve the energy efficiency and is well known for such applications. Expertise on combustion in pure oxygen exists, although for large-scale power generation other (new) technological challenges have to be met.

The main component of a conventional flue gas is nitrogen, since it is the main component ( $79 \%$ by volume) of the air used for combustion. In oxyfuel combustion, dilution of the flue gas by nitrogen is avoided by using oxygen produced from an air separation unit for combustion. Combusting the fuel using almost pure oxygen (95 to 99\%) at near-stoichiometric conditions, creates a flue gas consisting mainly of $\mathrm{CO}_{2}$ (> 90-95\% on a dry basis), water vapour and minor amounts of noble gases and, depending on fuel composition, $\mathrm{SO}_{\mathrm{x}}$ and $\mathrm{NO}_{\mathrm{x}}$. To control the combustion temperature, a proportion of the flue gas is recycled to the combustion process following energy extraction to the power cycle. After the water in the flue gas is condensed and the small amounts of impurities such as $\mathrm{SO}_{\mathrm{x}}, \mathrm{NO}_{\mathrm{x}}, \mathrm{O}_{2}$, noble gases, metals and particulates are removed to meet transport and storage requirements in addition to any safety and environmental requirements, the $\mathrm{CO}_{2}$ can be sent to storage.

There are different implications of oxyfuel combustion depending on the power cycle used, i.e., for a boiler or a gas turbine based system, see Figures 1 and 2. Combusting the fuel in a boiler requires slight modifications to the heat transfer surfaces to accommodate the change in composition and flow through the boiler and also modifications to the burner. The gas turbine based combined cycle requires modifications to the compressor, turbine, combustor, gas turbine cooling system and the heat recovery system as a result of the change of the properties of the gas passing through the turbine.

For boiler applications, the $\mathrm{O}_{2} / \mathrm{CO}_{2}$ recycle technology is, from a technical standpoint, feasible as either a retrofit option

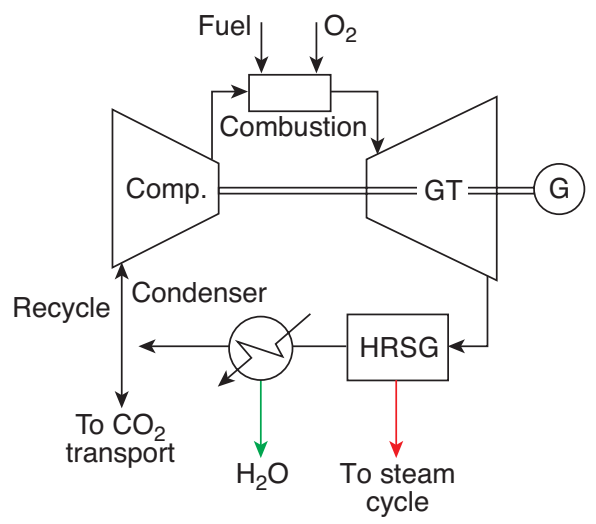

Figure 2

Simplified thermal cycle for oxyfuel-firing gas turbine based power generation.

for existing plants or for new plants. However, for the gas turbine based combined cycle, it is only possible to apply $\mathrm{O}_{2} / \mathrm{CO}_{2}$ recycle combustion to specially adapted new plants.

Air separation at the scale required for a full-scale power plant application can be performed using existing commercially available cryogenic technology. However, producing the oxygen with this technology results in an energy penalty that, together with the energy demand for $\mathrm{CO}_{2}$ compression and conditioning, results in a efficiency penalty compared to a power plant without $\mathrm{CO}_{2}$ capture. Other air separation technologies, with a high energy efficiency, are therefore of great interest and are the focus of considerable development effort but they are not yet suitable for large scale applications. On the positive side from an efficiency point of view is the reduced flue gas loss due to the reduced flue gas flow leaving the boiler (no dilution with nitrogen) leading to a high boiler efficiency. In all, the oxyfuel concept seems very competitive to the other options for $\mathrm{CO}_{2}$ capture and development and

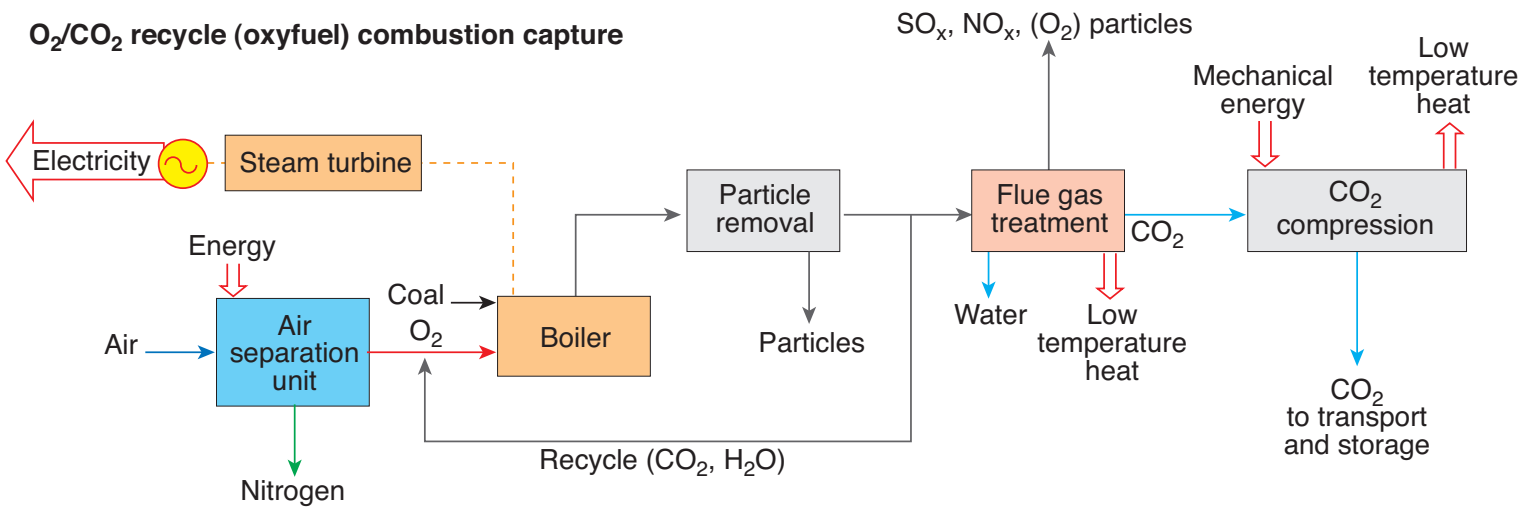

Figure 1

Principle of $\mathrm{O}_{2} / \mathrm{CO}_{2}$ recycle combustion illustrated for coal-fired boilers (courtesy Vattenfall). 
demonstration efforts are ongoing in Europe (in the ENCAP projects: oxyfuel PF and CFB boiler and AZEP project: oxyfuel GT with oxygen membrane technology), USA and Australia (Buhre et al., 2004).

\section{STATE-OF-THE-ART}

\subsection{Solid Fuel Fired Boiler Steam Cycle Applications}

Oxy-fuel firing has been used within the metal and glass manufacturing industries for some time, to achieve high temperatures, minimize energy losses and reduce emissions, but it has so far not been applied to full scale conventional steam boilers. In this case, all of the major components are available, at least in principle.

Theoretical studies have concentrated on the retrofit option, however, there are advantages in applying this to new and modern ultra-supercritical boilers since their increased efficiency reduces the oxygen demand per unit of generated electricity and therefore the cost end efficiency penalty of $\mathrm{O}_{2} / \mathrm{CO}_{2}$ recycle combustion (Jordal et al., 2004).

Combustion experiments on the laboratory scale and on small commercial stoker furnaces and pilot boilers (USA, Canada, Japan, Europe) have found it to be technically feasible (Chatel-Pelage, 2004).

An area for improvement of the oxyfuel power plant concept is to be found in the air separation unit. Improving the cost and power requirements of the present cryogenic air separation units is possible but limited. Development of new large-scale oxygen production concepts would be welcome, e.g. based on mixed oxygen conducting membranes (Kobayashi and Prasad, 1999; Smith and Klosek, 2001). There are also new processes were $\mathrm{O}_{2}$ is transferred from the air to a solid material that is then transferred to a separate reactor where the fuel reduces the solid material or the oxygen is released (Chemical looping combustion (Lyngfelt et al., 2001) or high temperature oxygen adsorption - CAR technology (Zeng et al., 2003)). These new technologies could lead to important breakthroughs if they can be scaledup from lab scale to commercial scale, with all the associated challenges (reliability over the long-term, effective energy requirement reductions in a life-cycle perspective), and possibility to be energy-effectively integrated in the power plant.

There are a number of oxyfuel conceptual developments, which could be potentially technical alternatives for $\mathrm{CO}_{2}$ capture from solid fuel-fired power generation. The conceptual developments have been focused on fully utilising the advantages of oxyfuel combustion for compact oxyfuel boilers, reducing the energy penalty of oxygen production, improving system efficiency by applying advanced power generation conditions, and enhancing multi-pollutants control combined with oxyfuel combustion. Most of these concepts are currently developing in conceptual proof or laboratoryscale evaluation.
An oxygen-fired circulating fluidised bed (CFB) boiler is considered as a viable option for near-term $\mathrm{CO}_{2}$ capture from power generation and other industrial applications (Nsakala et al., 2004). A CFB could in principal be better for the oxygen firing because the control of combustion temperature can be performed by a large stream of cooled furnace solids in addition of flue gas recirculation. A compacted CFB boiler can be designed compared with conventional PF boilers. A two-phase greenhouse gas emission control study was conducted by Alstom in collaboration with the U.S. DOE/NETL to evaluate the technical and economic feasibility and to perform CFB pilot tests to determine the impacts of the oxyfuel combustion. On the other hand, an effort on developing advanced oxyfuel boiler (Thompson et al., 2003) intended to avoid some limitations of the $\mathrm{O}_{2} / \mathrm{CO}_{2}$ recycle, although it is not very clear on the potentials of the application for solid fuel combustion.

Nevertheless, the following issues may also be important for implementing the applications of oxyfuel power plant concepts:

- The boiler has to be developed and optimised for this concept. More compact boilers could be constructed if close to stoichiometric combustion with minimum recycle.

- Adopting the available flue gas cleaning technologies to the requirements of the $\mathrm{CO}_{2}$ capture from the oxyfuel power generation in cost and energy effective ways.

- Dynamic behaviour and start-up and shut-down procedures need to be evaluated and developed.

- Combustion chemistry and kinetics need to be investigated in detail to provide design data. Material selection has to be considered in the new flue gas environment. Ash behaviour in the new combustion environment also needs to be analysed.

- Finding new integration possibilities with the power plant might be possible, especially if a new type of ASU is developed.

- Development of advanced oxyfuel boilers or heat exchangers to achieve a technology breakthrough on the $\mathrm{O}_{2} / \mathrm{CO}_{2}$ recirculation based oxyfuel boiler concepts.

Tests in pilot plants are necessary to judge the feasibility of the concept and to be able to investigate certain critical issues in a plant of relevant size. The long-term operational effects need to be investigated in a large-scale boilers during sufficient operational time.

\subsection{Gas Turbine Based Applications}

Oxyfuel combustion for a gas turbine based power generation involves a fossil fuel combusted using pure oxygen mixed with recycled $\mathrm{CO}_{2}$ rich flue gas. Therefore, the working fluid of the gas turbine is generally $\mathrm{CO}_{2}$-enriched gas and pure oxygen must be supplied for the combustion. Depending on the pure oxygen production or supply, the 
types of gas turbine based oxyfuel power cycles could be divided into two groups: the power cycles with external oxygen separation (external ASU), and the power cycles with an internal oxygen separation.

\subsubsection{Power Cycles with External Oxygen Separation}

As shown in Figure 2, a gas turbine based power cycle can be adapted with oxyfuel firing with external oxygen separation unit (ASU) to supply pure oxygen for the combustion. The typical cycles include the water cycle (Bolland et al., 2001), the Graz cycle (Bolland et al., 2001; Heitmeir and Jericha 2003; Hochenauer et al., 2004), and the Matiant cycle (Mathieu, 2003).

The water cycle is in principle a Brayton cycle, since pressure increase of water takes place through pumping in the liquid state. Evaporation takes place as the water acts as coolant to control the flame temperature in the first of two combustor chambers, where natural gas is burnt in high-purity oxygen. Expansion after the high-pressure combustion chamber starts at $871^{\circ} \mathrm{C}$, which must be said to represent very advanced steam technology. After the intermediate pressure combustion chamber, expansion begins at $1427^{\circ} \mathrm{C}$, which definitely represents gas turbine technology. After the expansion, water is condensed and recirculated in the cycle, and $\mathrm{CO}_{2}$ can be captured for further processing. Gross plant efficiency for this power cycle has been calculated as $51.7 \%$ without $\mathrm{CO}_{2}$ capture and compression and $40.5 \%$ with $\mathrm{CO}_{2}$ capture and compression. A conclusion (Bolland et al., 2001) was that the water cycle offered no efficiency advantages over a conventional combined cycle with post-combustion capture.

The Graz cycle was invented at the Technical University of Graz, and development of the cycle is an ongoing research project, where design of turbo machinery and heat exchangers is now underway. The Graz cycle has been presented in several versions in the literature. The common feature of the different versions is that both $\mathrm{CO}_{2}$ and water is recycled within the power cycle. Altogether, the Graz cycle is a kind of hybrid between steam and gas turbine cycles. The pressure of water is increased through pumping in the liquid state and the expansion partially takes place in a steam turbine. Thereafter the steam is mixed with combustion products in a combustion chamber and the subsequent expansion is in a turbine that must be said to represent gas turbine technology, although the steam content is much higher than what can be handled by present gas turbines. The net efficiency with $\mathrm{CO}_{2}$ capture and compression is $50-51 \%$. In a recent study steam turbine inlet temperature is $568^{\circ} \mathrm{C}$, and the condenser pressure is 0.25 bar which definitely represents what is feasible with present technology (Hochenauer et al., 2004). Recent data from the Technical University of Graz claim a thermal efficiency, including $\mathrm{CO}_{2}$ compression, of $55 \%$.

The Matiant cycle has its name after the inventors, Mathieu and Iantovski. The cycle is a Brayton-like recuperated cycle. The working fluid, mainly $\mathrm{CO}_{2}$, is compressed at low temperature with intercooling several times (to 300 bar), so that the $\mathrm{CO}_{2}$ in the liquid state can be removed and pumped for storage. After heating of the remaining highly pressurised fluid in a heat exchanger, expansion takes place down to 40 bar, prior to further heat exchange up till 900$1000^{\circ} \mathrm{C}$. Combustion with oxygen to $1300^{\circ} \mathrm{C}$ takes place in two consecutive combustion chambers with expansion between. After complete expansion in the second hightemperature turbine, cooling takes place through the heat exchange with the streams that are heated in the cycle, and thereafter water is condensed out. The net plant efficiency is around $44-45 \%$. The basic Matiant cycle does not really have any thermodynamic advantages (Bolland et al., 2001), and features a large amount of heat exchange between streams. The concept has been further developed into one more pure Brayton-type cycle (E-Matiant) and one combined cycle (CC-Matiant).

\subsubsection{Power Cycles with Internal Oxygen Separation}

Another type of gas turbine based oxyfuel power cycle has the oxygen supply integrated within the power cycle. A typical concept of this kind of power cycle is the so called Advanced Zero Emission Power Plant (AZEP) (Sundkvist $e t$ al., 2001). The AZEP concept was developed by Alstom Power (part of which is today owned by Siemens) and Norsk Hydro.

\section{COMPONENT AND PROCESS CONSIDERATIONS}

\subsection{General}

\subsubsection{Air Separation}

A variety of technologies have been developed to separate air. Among them, three main technologies have a large number of commercial references worldwide: cryogenic distillation, pressure swing adsorption and vacuum swing adsorption (Arpentinier, 2001). Polymeric membranes could be used for air-enrichment purpose. Each process has it's own advantages and drawbacks in terms of efficiencies, costs, operating range and economic point of view.

Pressure swing adsorption (PSA), vacuum swing adsorption (VSA) and membrane separation technologies are well-suited for small scale oxygen production $(<200 \mathrm{t} / \mathrm{d})$, whereas cryogenic plants can be designed for large-scale oxygen production (Fig. 3). Industrial sites exist with cumulative oxygen production of $30000 \mathrm{t} / \mathrm{d}$; currently, the largest oxygen production plant in the world is operated at a capacity of $4000 \mathrm{t} / \mathrm{d}$. Existing technologies would allow capacity up to $5000 \mathrm{t} / \mathrm{d}$. Design studies for $7000 \mathrm{t} / \mathrm{d}$ by a single train have been performed. Nevertheless, once $\mathrm{CO}_{2}$ transport networks have been developed, decentralised power generation from 
oxycombustion could be deployed, in which case PSA or VSA technologies could prove viable.

As a consequence, cryogenic distillation is currently the only proven option for oxycombustion power plant at an industrial scale.

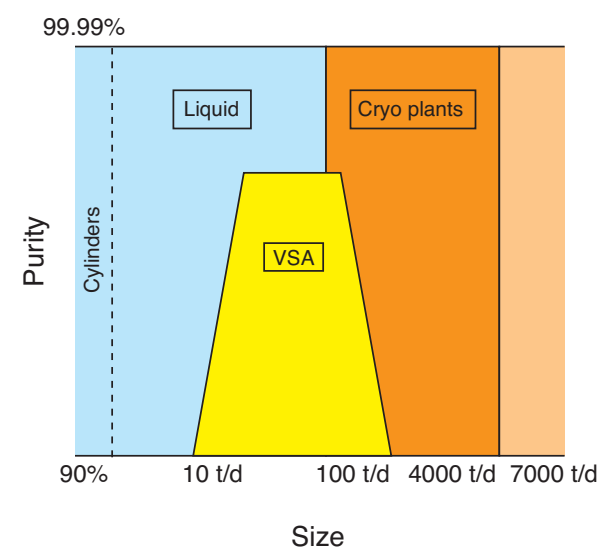

Figure 3

Oxygen production technology selection as a function of quantity.

\section{Cryogenic Distillation: Basic Facts}

In cryogenic air separation, gas is in fact separated as liquids, so very low temperature is used.

Typical steps in cryogenic air separation are (see Figs 4 and 5):

- Air compression. Most ASUs operate at about 6 bar.

Higher pressures are requireds:

- when desired products are liquids, which should not be the case for oxycombustion applications,

- in the case of IGCC to optimise integration by use of pressurized nitrogen.
Axial or centrifugal compressors can be used, depending on size.

- Air purification. Although air contains mainly oxygen and nitrogen, several other kinds of components are present that have to be removed before the air stream enters the heat exchanger and the distillation column. $\mathrm{CO}_{2}$ and $\mathrm{H}_{2} \mathrm{O}$, as well as $\mathrm{NO}_{\mathrm{X}}$ and hydrocarbon traces, must be removed for safety reasons. Indeed, their freezing point is far above the air liquefaction temperature. Up-to-date purificationtechnology is adsorption (using beds of alumina, molecular sieve).

- Heat exchange. After purification, air is cooled to its dew point by heat exchange with the products.

- Cold generation. Cold temperatures required for the liquefaction steps are achieved (in large ASUs) by the use of expansion turbines or of turbo-expanders. Through the Joule-Thomson effect, drop in pressure induces a drop in temperature. Work developed by expansion is generally recovered to drive compressors.

- Cryogenic production: remaining air components are finally separated in one or more distillation columns.

\section{Energy Consumption}

Energy consumption (see Fig. 6) - mostly electrical power to drive the air compressors - is mainly influenced by two parameters:

- The required oxygen pressure if pressurized boilers are developed.

- The required oxygen purity. This will mainly result from a balance with the energy requirements of the $\mathrm{CO}_{2}$ train: the purer the oxygen (say $99 \%$ oxygen is used), the lower the $\mathrm{CO}_{2}$ compression energy use.

If energy to power the ASU is taken from the grid, additional $\mathrm{CO}_{2}$ emissions due to the ASU will greatly depend on the energy mix for electricity generation at a given location (from about $0.1 \mathrm{t} \mathrm{CO}_{2} / \mathrm{MWh}_{\mathrm{e}}$ in countries where nuclear generation share is important to $0.6-0.7 \mathrm{t} \mathrm{CO}_{2} / \mathrm{MWh}_{\mathrm{e}}$ in countries relying heavily on coal).

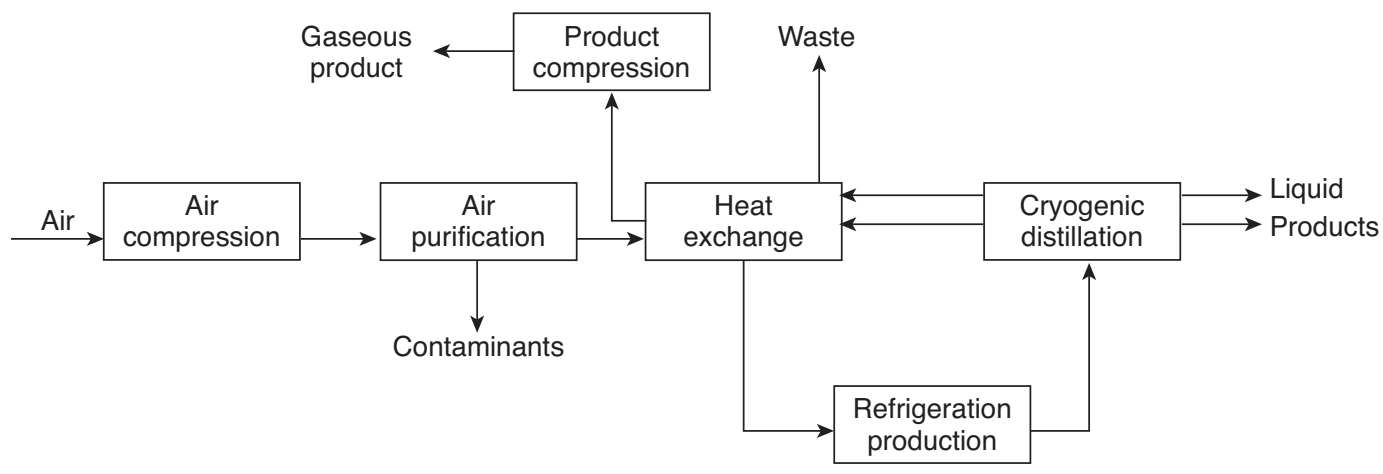

Figure 4

Generic process flow of an ASU (Courtesy Air Liquide). 


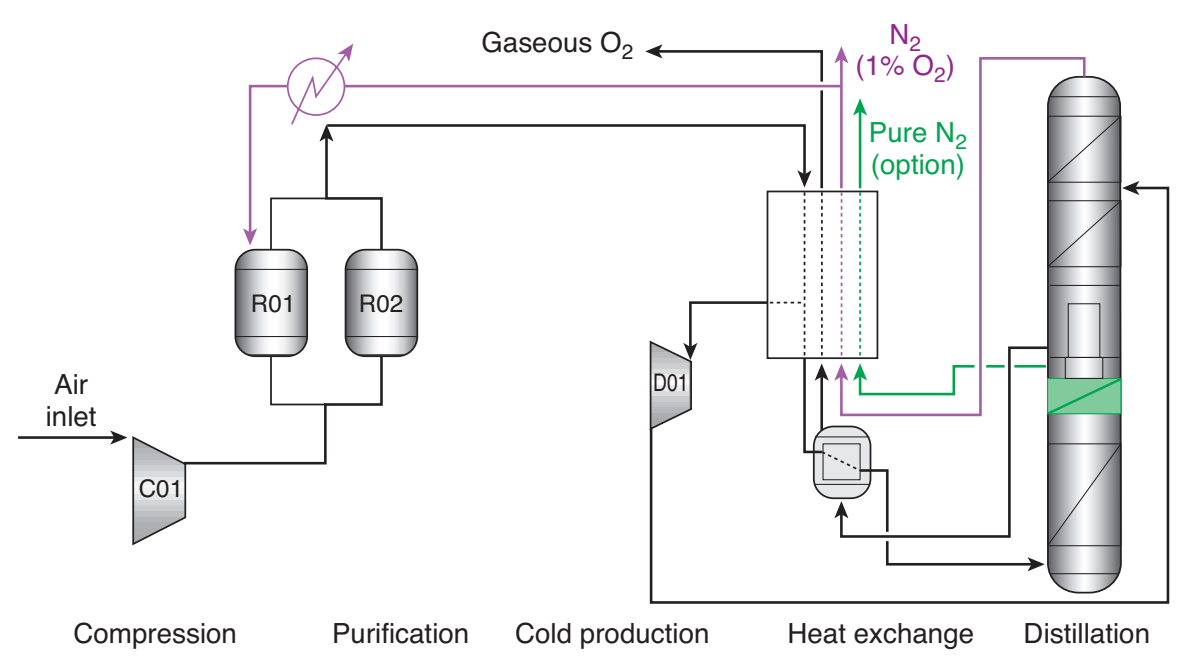

Figure 5

ASU diagram (Courtesy Air liquide).

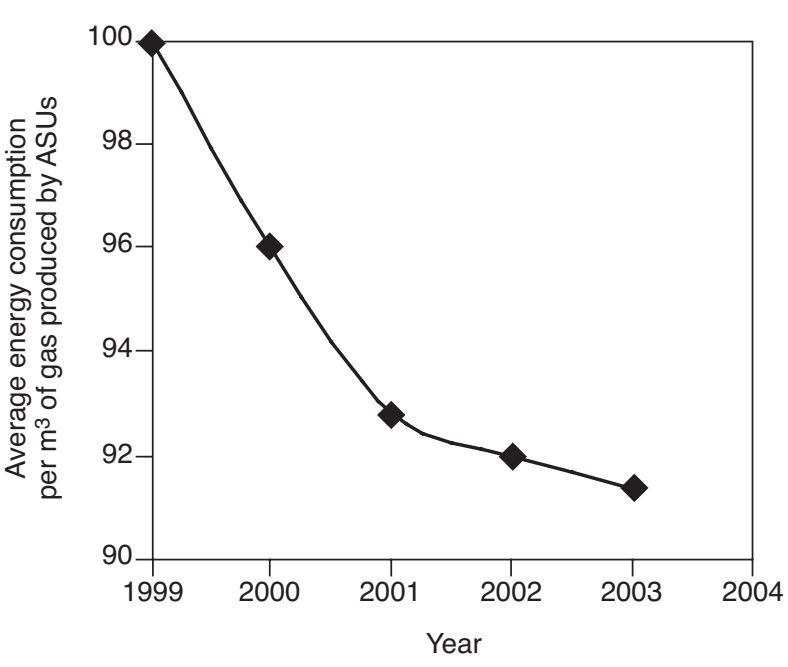

Figure 6

Recent trends in specific energy consumption for ASUs (base 100 in 1999; source: Air liquide).

\section{Reliability, Safety}

Large scale (i.e. with on-stream factor up to 8500 hours/year) oxygen production using cryogenic technology can be sustained for decades, which is the correct time frame for power plants. Any new technology must cope with such requirements (minimization of shut-down periods for maintenance, of O\&M costs), especially if the ASU is integrated with the power plant itself. Moreover, cryogenic ASU can also be operated to produce its own back-up oxygen to ensure continuous supply.
Present cryogenic units are able to produce more than $4000 \mathrm{t} \mathrm{O}_{2} / \mathrm{d}$ for long periods with no major safety or maintenance problems, and this mature technology is still improving after one century.

Environmental impacts of ASUs are minor and well managed by the industry, which has developed standards [EIGA94/03].

Main Development Trends

The main development trends are directed toward:

- Larger ASUs.

- Optimisation of heat exchangers.

- New oxygen processes are being developed, mainly through the use of ceramic membranes.

Integration of ASUs to the power generation system

ASUs are already well optimised units. Nevertheless, integration with other parts of the overall process is possible and should be looked for. As by-product of the $\mathrm{O}_{2}$ production unit, nitrogen will be available that can be used-as in Integrated Gasification Combined Cycle plants_-as a fuel carrier, as a sweep gas, as a mean to reduce $\mathrm{NO}_{\mathrm{X}}$ formation in combustion chambers of gas turbines and, of course, as an inert gas for safety issues. More generally, there is a lot of experience within the industry with the optimisation of Air Separation Units regarding local conditions.

\subsection{2 $\mathrm{CO}_{2}$ Conditioning}

$\mathrm{CO}_{2}$-rich flue gases leaving the power plant can be cleaned up and condensed using basic processes in the $\mathrm{CO}_{2}$ conditioning island (Fig. 7). When leaving this unit, $\mathrm{CO}_{2}$ enters the transport (or temporary storage) unit.

The design of the $\mathrm{CO}_{2}$ conditioning unit will be influenced by several factors: 
- Requirements for the final $\mathrm{CO}_{2}$ stream. This is likely to depend on several factors such as final use (pure storage/EOR/ECBM/EGR), transport conditions and material, safety requirements (which may depend on population density and vary from one country to another).

- Fuel type (natural gas, low-sulphur coal, high-sulphur coal, oil, etc.) and flue gas treatments will influence the composition of the $\mathrm{CO}_{2}$-rich stream.

- Transport type (pipeline, vessel at 20 bar, vessel at 7 bar) will influence the choice of process (liquefaction/ compression).

- $\mathrm{CO}_{2}$ capture rate, which will depend on initiatives for $\mathrm{CO}_{2}$ emission abatement and on abatement strategies.

The $\mathrm{CO}_{2}$ conditioning island can include several steps. Actual design cannot be defined outside a case by case assessment, since numerous factors-ranging from technology options to regulations-will impact the decision-making framework. Those steps are:

- $\mathrm{CO}_{2}$-rich flue gas cooling. Low temperature heat may be recovered for further integration.

- Flue gas treatment. In oxycombustion power plants, flue gas volume to be handled is reduced, resulting in energy and financial savings. This step also strongly depends on the requirements for the final $\mathrm{CO}_{2}$ stream (depending on the feasibility of co-storage) (Anheden et al., 2004; Haines et al., 2004).

- $\mathrm{DeNO}_{\mathrm{X}}$. As combustion in an oxygen atmosphere reduces largely thermal $\mathrm{NO}_{\mathrm{X}}$ formation (since oxidant media does not anymore contain nitrogen), a $\mathrm{DeNO}_{\mathrm{X}}$ unit is unlikely to be required. This point will depend greatly on the fuel burned and on the burner technology.

- $\mathrm{DeSO}_{\mathrm{X}}$ Low $\mathrm{SO}_{\mathrm{X}}$ levels meeting regulatory requirements can be achieved using existing technologies. One important issue is the co-storage of $\mathrm{SO}_{\mathrm{X}}$ (and possibly $\mathrm{NO}_{\mathrm{X}}$ ) with $\mathrm{CO}_{2}$.

- Removal of particulates, heavy metals.

- Compression of $\mathrm{CO}_{2}$ can be performed by use of centrifugal compressors. Sizes are in the range of current industry practice.

- A drying unit may be used, depending on the water content allowed in the $\mathrm{CO}_{2}$ stream for the downstream system (transport/injection facilities). Basically, water levels of $600 \mathrm{ppm}$ may be reachable by knocking out water between the first compression steps. If lower levels (50-60 ppm) are required, a drier will have to be added to the $\mathrm{CO}_{2}$ conditioning plant. Usual driers use glycol or triethylene glycol (TEG) loops working between 30-60 bar. Adsorption could also be used.

\section{Energy Consumption of the Compression Step}

Compression step will require about $(80 \mathrm{kWh}-120 \mathrm{kWh})$ per ton of $\mathrm{CO}_{2}$ captured (see Fig. 8), depending on:

- Compressor efficiency,

- $\mathrm{CO}_{2}$-rich stream composition,

- Outlet pressure required,

- Integration opportunities.

For instance, for an on-stream factor of $90 \%$ and volume of captured $\mathrm{CO}_{2}$ amounting to $1 \mathrm{Mt} / \mathrm{year}$, this average corresponds to an installed power of $12.5 \mathrm{MW}$.

Detailed analysis will depend on local conditions, particularly fuel/electricity availability to drive the compressors and cooling water temperature.

\section{Integration of the Compression Step}

Compression produces low-grade heat that can be recovered for instance to heat water for local (municipal) heating, or to

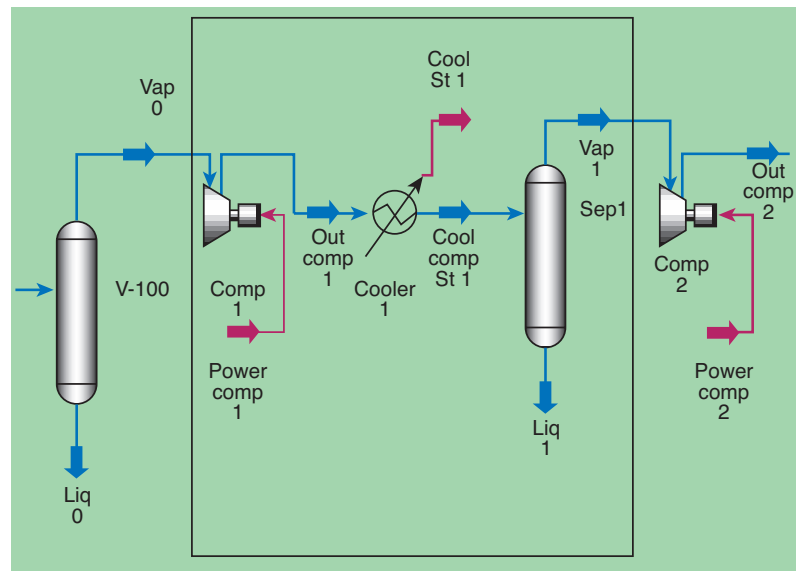

Figure 7

Typical interstage step of the compression island.

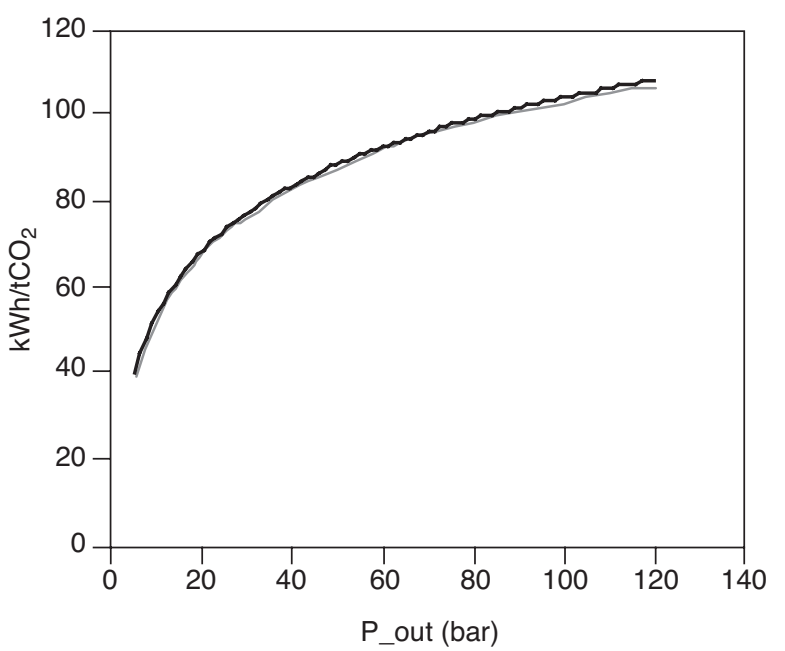

Figure 8

Typical shape of energy requirements for $\mathrm{CO}_{2}$ compression (courtesy Air Liquide). 
pre-heat fuel or vapour. The heat can also be used for steam cycle feed-water preheating and thereby reduce the amount of steam extracted from the steam turbine.

\subsection{Solid Fuel Fired Boiler Steam Cycle Applications}

A number of aspects are important for the process considerations of the solid fuel oxygen-firing steam cycle applications.

\subsubsection{Boiler Heat Transfer Areas}

Combusting the fuel with almost pure oxygen, combined with $\mathrm{CO}_{2}$ recirculation, produces gases of different physical and thermal properties which can cause significant differences in the heat transfer processes in the steam generator unit. When performing the heat transfer analysis, a model that accounts for three modes of heat transfer in the upper furnace and convective pass of the unit (direct radiation, nonluminous radiation and convection) has to be used. The presence of higher concentrations of $\mathrm{CO}_{2}, \mathrm{H}_{2} \mathrm{O}$ and $\mathrm{SO}_{2}$ increases the non-luminous radiation. The choice of recycle rate also affects the heat transfer by controlling the flame temperature and volume flow through the furnace. In general, the retrofit studies performed have shown an increase in heat transfer rates but they are not deemed to require any major modifications. In the design of a new boiler, the desired heat transfer rates can already be accommodated in the design phase.

The boiler efficiency is also increased due to a lower flue gas loss.

\subsubsection{Flue gas recirculation and heat recovery}

The oxyfuel recycle combustion boiler has to be fitted with flue gas recirculation and a booster fan to overcome the additional pressure drop in the heat exchangers and ducts. Additional heat exchangers are also required to recover the heat in the flue gas for pre-heating oxygen and feedwater and to condense the steam in the flue gas.

\subsubsection{Boiler Air in-Leakage}

It is important to ensure that the boiler air in-leakage should be controlled as low as possible since the air dilutes the $\mathrm{CO}_{2} / \mathrm{H}_{2} \mathrm{O}$ mixture in the boiler and thereby makes separation of $\mathrm{CO}_{2}$ more difficult. This is a major obstacle when it comes to retrofitting $\mathrm{O}_{2} / \mathrm{CO}_{2}$ recycle combustion operation to existing boilers, which could have air in-leakage rates of $8-16 \%$. New boilers will not encounter this problem to the same extent and can easily be designed with this in mind from the beginning.

Without air in-leakage, the only gas components, in addition to those created by the combustion process, are argon and nitrogen. These are easily bled off during the condensation of the $\mathrm{CO}_{2}$ following compression although the extra non-condensable gases increase the compressor duty and the energy consumption of the $\mathrm{CO}_{2}$ purification. However, studies reveal that the extra energy requirement is counterbalanced by the reduced energy needed for air separation, which is an important factor to be also considered (Wilkinson et al., 2001).

\subsubsection{Slagging and Fouling}

There are indications from experimental work on the oxyfuel combustion of coal that fouling and, for some coals, the slagging propensity (Babcock Energy et al., 1995) may be increased. Further investigation is needed.

\subsection{5 $\mathrm{NO}_{\mathrm{x}}$}

The $\mathrm{NO}_{\mathrm{x}}$ formation, when applying $\mathrm{O}_{2} / \mathrm{CO}_{2}$ recycle combustion, is expected to be lower since the nitrogen supplied by the air is removed, thus eliminating the thermal $\mathrm{NO}_{\mathrm{x}}$ formation, although the possibility of $\mathrm{NO}_{\mathrm{x}}$ formation from fuel-bound nitrogen remains. For coal combustion, it is estimated that about $60-90 \%$ of the total $\mathrm{NO}_{\mathrm{x}}$ emission is derived from the fuel $\mathrm{NO}_{\mathrm{x}}$. Combustion experiments have shown a $\mathrm{NO}_{\mathrm{x}}$ reduction (in $\mathrm{mg} / \mathrm{MJ}$ ) of about $60 \%$ but a zero reduction in $\mathrm{NO}_{\mathrm{x}}$ level has also been observed (Woycenko et al., 1995; Croiset et al., 2000; 2001; Babcock Energy et al., 1995). On the other hand, the concentration of $\mathrm{NO}_{\mathrm{x}}$ is higher in the oxy-fuel case since the $\mathrm{NO}_{\mathrm{x}}$ is not diluted by nitrogen from the air. This applies if the $\mathrm{NO}_{\mathrm{x}}$ is not removed prior to recirculation of the flue gas.

\subsubsection{SO}

The generation of $\mathrm{SO}_{\mathrm{x}}$ from fuel bound sulphur is not significantly affected by the application of oxy-fuel combustion. However, the concentration of $\mathrm{SO}_{\mathrm{x}}$ is higher than for normal combustion since it is not diluted by nitrogen from the air. This combined with the moisture content of flue gas affects the acid dew point in the boiler.

It has been suggested that the $\mathrm{SO}_{2}$ could be stored together with the $\mathrm{CO}_{2}$ since it has similar physical properties. This would eliminate the need for a flue gas desulphurisation unit which accounts for a relatively large proportion of the investment cost and internal energy consumption. However, the viability of co-storing $\mathrm{CO}_{2}$ and $\mathrm{SO}_{2}$ from a transport, storage and legal perspective is uncertain. (Knauss et al., 2001; Anheden et al., 2004). This is likely to vary with the location and storage type. This issue will probably be studied more in depth in future projects.

The above factors, together with the process conditions (higher $\mathrm{CO}_{2}$ and $\mathrm{SO}_{\mathrm{x}}$ concentrations than in conventional boiler) will determine the choice and design of a $\mathrm{SO}_{\mathrm{x}}$ removal process, if required.

\subsubsection{Operational Characteristics}

Dynamic behaviour and start-up and shut-down procedures need to be evaluated and developed as well as safety systems. 
Tests in pilot plants are necessary to judge the feasibility of the oxyfuel boiler concept and to be able to investigate certain critical issues in a plant of relevant size. The long term operational effects need to be investigated in a large scale boiler during sufficient operational time.

\subsection{Gas Turbine Based Applications}

\subsubsection{Compressor and Turbine}

In comparison of $\mathrm{CO}_{2}$ to air, the most significant differences of their physical properties are found in density, heat capacity, the isentropic exponent and the speed of sound. This results in a complete new design of the compression and turbine section. When $\mathrm{CO}_{2}$ is used as a working fluid, generally a higher pressure ratio than with air should be applied.

\subsubsection{Start-up and Shut-down Procedures}

New procedures for starting up and shutting down the gas turbine have to be identified. The unit will have to be started up on $\mathrm{CO}_{2}$, which would require a $\mathrm{CO}_{2}$ storage tank at the plant site.

\section{DEVELOPMENT OPTIONS}

As mentioned in section 2.1, development of new large-scale non-cryogenic oxygen production technologies is one of the important issues to reduce the energy penalty for the oxygen production. A promise of less expensive oxygen production significantly affects the applications of the oxyfuel combustion technology. Currently the oxygen ion mixed-conducting ceramic membrane technology is being developed and is generally considered as one having great potential to replace the cryogenic technology for large-scale industrial oxygen production (Balachandran et al., 1998; Armstrong et al., 2002) although the technology is generally at the early stages of maturity under a pre-commercial demonstration status. This large scale target—typically $10000 \mathrm{tO}_{2} /$ day for a $500 \mathrm{MW}$ coal-fired power plant-is a key issue to fit oxyfuel combustion for energy production. Cryogenic ASUs benefit from single-train capacity increase while this scaling effect is more questionable with paralleling ceramic membranes modules (see Fig. 9).

The ceramic membrane technology for oxygen production is based on a type of special materials (perovskites with complex formulations $\left.(\mathrm{La}, \mathrm{Sr})(\mathrm{Fe}, \mathrm{CoCu}, \mathrm{Cu}) \mathrm{O}_{3-\delta}\right)$, which have both electronic and oxygen ionic conductivity when operated at high temperatures (around 700 to $900{ }^{\circ} \mathrm{C}$ ). During the operation, oxygen molecules adsorb onto the surface of the ceramic membrane, where the oxygen molecules are dissociated and ionised by electron transfer from the membrane. Under a gradient of oxygen partial pressure on the opposite side of the membrane, oxygen ions are transferred within the lattice of the material, then release the electrons and form oxygen molecules again. The mixed oxygen-ion conducting ceramic membrane technology has a very high selectivity for oxygen separation. In contrast to conventional membrane processes, the driving force of electrochemical process makes the oxygen flux in the ceramic membrane dependant on the natural $\log$ of oxygen partial pressure ratio. Therefore the electrolytic membranes have much high fluxes than that in conventional membrane processes (Allam et al., 2004). That is the major reason why the ceramic membrane technology is considered as a promising technology for large-scale oxygen production. However, oxygen separation using the ceramic membrane technology is still a relatively energy intensive process. A way to reduce the energy penalty is to integrate

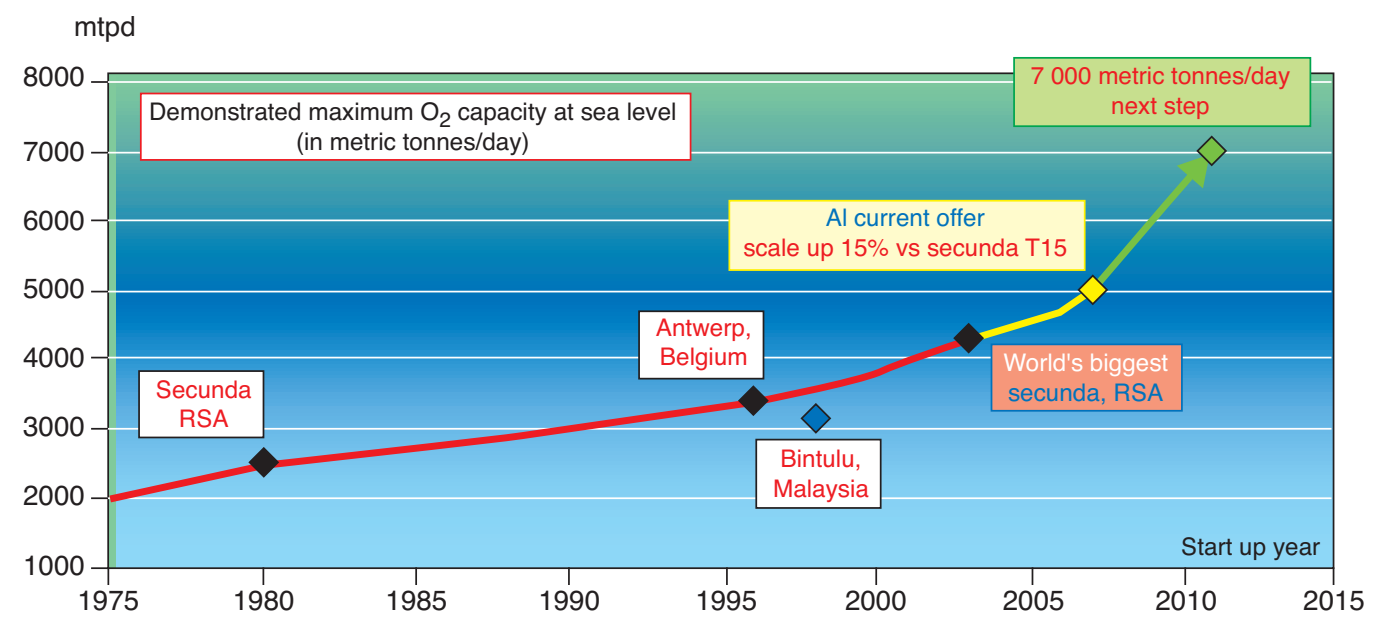

Figure 9

Trends in oxygen production capacity by cryogenic ASUs (Source: P. di Zanno 2004). 
with thermal power cycle for energy recovery. In addition, most of the applications of the membrane technology are now considered to integrate with gas turbine based power cycles using gaseous fuels. It is expected that more complicated situations may need to be handled when the membrane technology is integrated with coal-fired oxyfuel combustion.

Two major research and development teams currently work on the development of mixed conducting ceramic membrane technology for oxygen production. One team is supported by U.S. DOE's NETL. Their commercial development focused on oxygen separation and production from air. Another team is lead by Praxair and BP. Most of the studies are focusing on syngas and related applications. The commercialization of the mixed conducting ceramic membrane technology is now underway for such applications, and will be continued on scale-up oxygen production and implementing the fabrication of membrane devices (Thompson et al., 2003). Since 1998, the US DOE has supported a three phase cooperative program on the oxygen-ion conducting ceramic membrane technology (Armstrong et al., 2002; Allam, 2002).

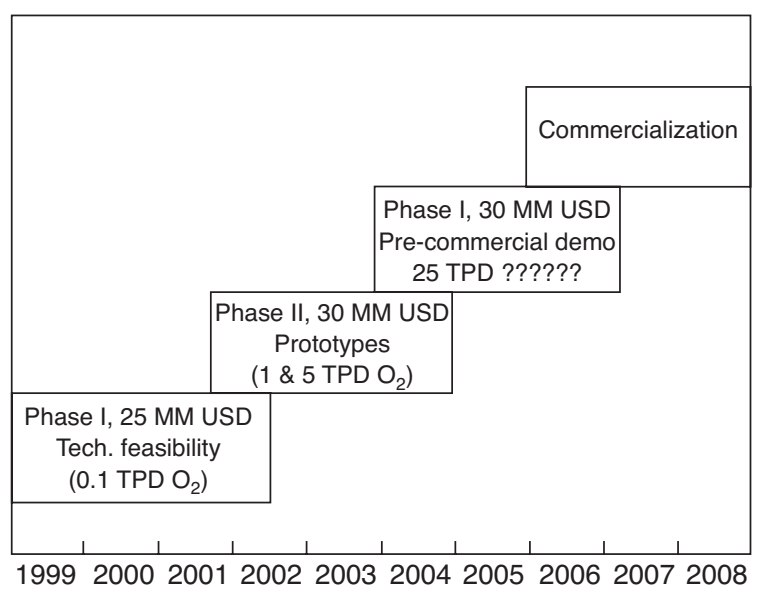

Figure 10

The time schedule of the program for the development of oxygen-ion conducting membrane technology and commercialization. (Armstrong et al., 2002; Allam, 2002).

The time schedules for the development of technology and commercialization are shown in Figure 10. According to this time schedule, and the fabrication characteristics of the membrane technique, there may be a long way to reach a typically oxygen production scale of $10000 \mathrm{tO}_{2}$ /day for a $500 \mathrm{MW}$ coal-fired power plant during the scale-up development.

Another important aspect for the development of oxygen transfer membrane technology is how to integrate the membrane technology with the power plant. The goal should be to create an overall power plant concept that can operate at high efficiency and at the same time accommodate for the operational demands for the membranes such as operating temperature and pressure and gaseous working environment. This is indeed a challenging task, especially for solid fuel fired power plants.

\section{REFERENCES}

Allam, R.J.(2002) Industrial aspects of membrane development for oxygen separation. Membrane Gas Separation for Sustainable Fuel Production and Power Generation, Seminar in Oslo, 25-26 November.

Allam, R.J., McDonald, C.J., White, V. (2004) Oxyfuel conversion of refinery process equipment utilising flue gas recycle for $\mathrm{CO}_{2}$ capture. The 7th International Conference on Greenhouse Gas Control Technologies (GHGT7), Vancouver, Canada, September 5-9.

Anheden, M., Andersson, A., Bernstone, C., Eriksson, S., Yan, J., Liljemark, S., Wall, C. (2004) $\mathrm{CO}_{2}$ quality requirement for a system with $\mathrm{CO}_{2}$ capture, transport and storage. The 7 th International Conference on Greenhouse Gas Control Technologies (GHGT7), Vancouver, Canada, September 5-9.

Armstrong, P.A., Stin, Van E.E., Bennett, D.L., Foster, E.P. (2002) Ceramic membrane development for oxygen supply to gasification applications. Gasification Technologies 2002, San Francisco, 27-30 October.

Arpentinier Ph. (2001) The Technology of Catalytic Oxidations, Ph. Arpentinier, ed. Technip. For a clear insight into ASUs technologies and development, see tome 1, chap. 3.

Babcock Energy Limited, Air Products PLC, University of Ulster; University of Naples. (1995) Pluverised coal combustion system for CO2 capture. Final Report, JOULE II Programme, Clean Coal Technology R\&D Contract No. JOU2-CT92-0062, October 1995.

Balachandran, U., Ma, B., Maiya, P.S., Mieville, R.L., Dusek, J.T., Picciolo, J.J., Guan, J., Dorris, S.E., Liu, M. (1998) Development of mixed-conducting oxides for gas separation. Solid State Ionics ,108, 363-370.

Bolland, O., Kvamsdal, H.M., Boden, J.C. (2001) A thermodynamic comparison of the oxy-fuel power cycles Water Cycle, Graz Cycle and Matiant Cycle. The proceedings of the International Conference Power Generation and Sustainable Development, Liège, Belgium, October 8-9.

Buhre, B.J.P., Elliott, L.K., Sheng, C.D., Gupta, R.P., Wall, T.F. (2004) Oxy-fuel combustion technology for coal-fired power generation. Cooperative Research Centre for Coal in Sustainable Development, Dept. of Chemical Engineering, The University of Newcastle, Callaghan NSW 2308, Australia.

Chatel-Pelage, F. (2004) Oxycombustion process in pulverized coal-fired boilers, F. Chatel et al., paper \& presentation, 29th International conference on Coal Utilization and Fuel Systems, Clearwater.

Croiset, E., Thambimuthu, K.V., Palmer, A. (2000) Coal combustion in $\mathrm{O}_{2} / \mathrm{CO}_{2}$ mixtures compared with air. Canadian J Chem Eng., 78, 402-407.

Croiset, E., Thambimuthu, K.V. (2001) NOx and SO2 emissions from $\mathrm{O}_{2} / \mathrm{CO}_{2}$ recycle coal combustion, Fuel, 80, 2117-2121.

EIGA 94/03 Environmental impacts of air separation units, IGC Doc 94/03/E, European Industrial Gases Association

Di Zanno, P., Cottereau A. (2004) Presentation to "Les Journées du Pétrole", AFTP conference, Paris, October 2004.

Haines, M., Leslie, J., Macdonald, D. (2004) Co-capture and storage of $\mathrm{CO}_{2}$ with other impurities from coal and heavy fuelfired power plant flue gases. The 7th International Conference on Greenhouse Gas Control Technologies (GHGT7), Vancouver, Canada, September 5-9. 
Heitmer, F., Jericha, H. (2003) Graz cycle - an optimised power plant concept for $\mathrm{CO}_{2}$ retention. First international conference on Industiral GT Technologies, RTD Framework Programme of the European Union, Brussel, July 2003.

Hochenauer, C., Hohenwarter, U., Sanz, W., Schlamadinger, B. (2004) Bio-energy cogeneration systems with $\mathrm{CO}_{2}$ separation and storage. To be presented at the ASME Turboexpo 2004, Vienna, Austria, Paper No GT2004-54224.

Knauss, K.G., Johnson, J.W., Steefel, C.I., Nitao, J.J. (2001) Evaluation of the impact of $\mathrm{CO}_{2}$, aqueous fluid and reservoir rock interactions on the geologic sequestration of $\mathrm{CO}_{2}$, with special emphasis on economic implications. 1st National Conference on Carbon Sequestration, NETL Publications, 2001. Available at: http://www.netl.doe.gov/publications/proceedings/01/carbon_seq/p26.pdf

Kobayashi, H. and Prasad, R. (1999) A review of oxygen combustion and oxygen production systems. Proceedings of Forum on High Performance Industrial Furnace and Boiler. Tokyo, Japan, March 8-9.

Jordal, K., Anheden, M., Yan, J., Strömberg, L. (2004) Oxyfuel combustion for coal-fired power generation with $\mathrm{CO}_{2}$ capture Opportunities and challenges. The 7 th International Conference on Greenhouse Gas Control Technologies (GHGT7), Vancouver, Canada, September 5-9.

Lyngfelt, A., Leckner, B., Mattisson, T.(2001) A fuidized-bed combustion process with inherent $\mathrm{CO}_{2}$ separation; application of chemical-looping combustion. Chem. Eng. Sci. 56: 3101-3113,

Mathieu, P. (2003) Mitigation of $\mathrm{CO}_{2}$ emissions using low and near zero $\mathrm{CO}_{2}$ emission power plants. Clean Air, Int. J. on Energy for a Clean Environment, 4, 1-16.
Nsakala, N.Y., Liljedahl, G.N., Marion, J., Levasseur, A.A., Turek, D., Chamberland, R., MacWhinnie, R., Morin, J.-X., Cohen, K. (2004) Oxygen-fired circulating fluidized bed boilers for greenhouse gas emissions control and other applications. Third Annual Conference on Carbon Capture and Sequestration. Alexandria, VA, USA, May 3-6.

Smith, A.R. and Klosek, J. (2001) A review of air separation technologies and their integration with energy conversion processes. Fuel Processing Technology, 70, 115-134.

Sundkvist, S.G., Griffin, T., Thorshaug, N.P. (2001) AZEP development of an integrated air separation membrane - gas turbine. Second Nordic Minisymposium on Carbon Dioxide Capture and Storage, Chalmers University of technology, Göteborg, Sweden, October 26.

Thompson, D.R., Bool, L.E., Christie, G.M. (2003) Advanced oxyfuel boilers and process heaters for cost effective $\mathrm{CO}_{2}$ capture and sequestration. Annual Technical Progress report. DOE Award No. DE-FC26-01NT41147, Parxair, Inc., July 2003.

Wilkinson, M.B., Boden, J.C., Panesar, R.S., Allam, R.J. (2001) $\mathrm{CO}_{2}$ capture via oxyfuel firing: optimisation of a retrofit design concept for a refinery power station, 1 st National Conference on Carbon Sequestration, Washington DC, USA, 15-17, May.

Zeng, Y. Tamhankar, S., Ramprasad, N., Fitch, F., Acharya, R., Wolf, R. (2003) A novel cyclic process for synthesis gas production. Chem. Eng. Sci. 58, 577-582.

Final manuscript received in May 2005 or distributed for profit or commercial advantage and that copies bear this notice and the full citation on the first page. Copyrights for components of this work owned by others than IFP must be honored. Abstracting with credit is permitted. To copy otherwise, to republish, to post on servers, or to redistribute to lists, requires prior specific permission and/or a fee: Request permission from Documentation, Institut français du pétrole, fax. +33147527078 , orrevueogst@ifp.fr. 